\title{
LIVING YOUR BEST LIFE AND RADIATING POSITIVITY: EXPLORATORY CONCEPTIONS OF WHOLESOME MEMES AS “THE NEW SINCERITY”
}

\begin{abstract}
From commercial advertising to political messaging, internet memes have proven to be among the most prevalent and pervasive forms of communication online. The so-called "wholesome meme" is a subversive genre of meme that arose in early 2016 as a reaction to increasing geopolitical turbulence and cultural polarization. Wholesome memes are defined by their bold positivity and feature loving friendships, cute animals, and heartwarming stories. As an early attempt to theorize this emerging phenomenon, this paper argues that wholesome memes can be considered part of the larger post-postmodernist literary movement, The New Sincerity. Synthesizing expressions of irony and sincerity, these memes may signal a shift in the character and attitude of internet culture from anti- to pro-social and speak to the desire of people to seek meaning and fulfillment.
\end{abstract}

\section{Studying wholesome memes in the Library and Information Science context}

Why study memes in the context of Library and Information Science (LIS)? Largely because memes are documents carrying units of communicative intent that could be considered information. Moreover, wholesome memes are particularly interesting in that their creation and consumption speaks to the desire of people to seek genuine human connection, authenticity, meaning, and fulfillment. This connects to a larger trend in LIS research that is engaged with larger questions about the role of information, media, and technology in the pursuit of the "higher things in life" (Kari \& Hartel, 2007). In an attempt to begin to describe and characterize these communicative documents, a preliminary textual analysis was performed on memes found on the r/wholesomememes subreddit, two Facebook groups entitled Wholesome Memes (facebook.com/wholesomememers and facebook.com/memewholesome), and a Tumblr blog dedicated to wholesome memes (wholesome-memes-only.tumblr.com). Textual analysis involves describing and interpreting the characteristics in textual and visual works (Frey, Botan, \& Creps, 1999).

\section{Understanding wholesome memes}

Mimicking a biological evolutionary process (Heylighen \& Chielens, 2009), internet memes have developed over time into a wide variety of genres. Each genre is formed and continually shaped by the online communities where the memes are created, as well as by popular media, current events, and society at large. Of particular interest here is the genre of so-called 
"wholesome memes" as a distinct category conveying a unique wholesome message and a complimentary visual aesthetic.

While wholesome memes are similar to other types of memes in that they convey a message or experience succinctly through the use of (repeated or re-used) images and texts, they are primarily defined by their bold positivity (Figure 1). The r/wholesomememes subreddit, a popular online community creating and sharing wholesome memes, outlines some key characteristics: wholesome memes are memes that "promote health or well-being of body, mind, and/or soul" and that are "pure of heart, devoid of corruption or malice, modest, stable, virtuous, and all-around sweet and compassionate" (n.d.). They "advocat[e] self-respect, hard work, active listening, healthy relationships, and balanced diets" (Hunt, 2016) and "promote earnest messages of empowerment" (Eadicicco, 2017).
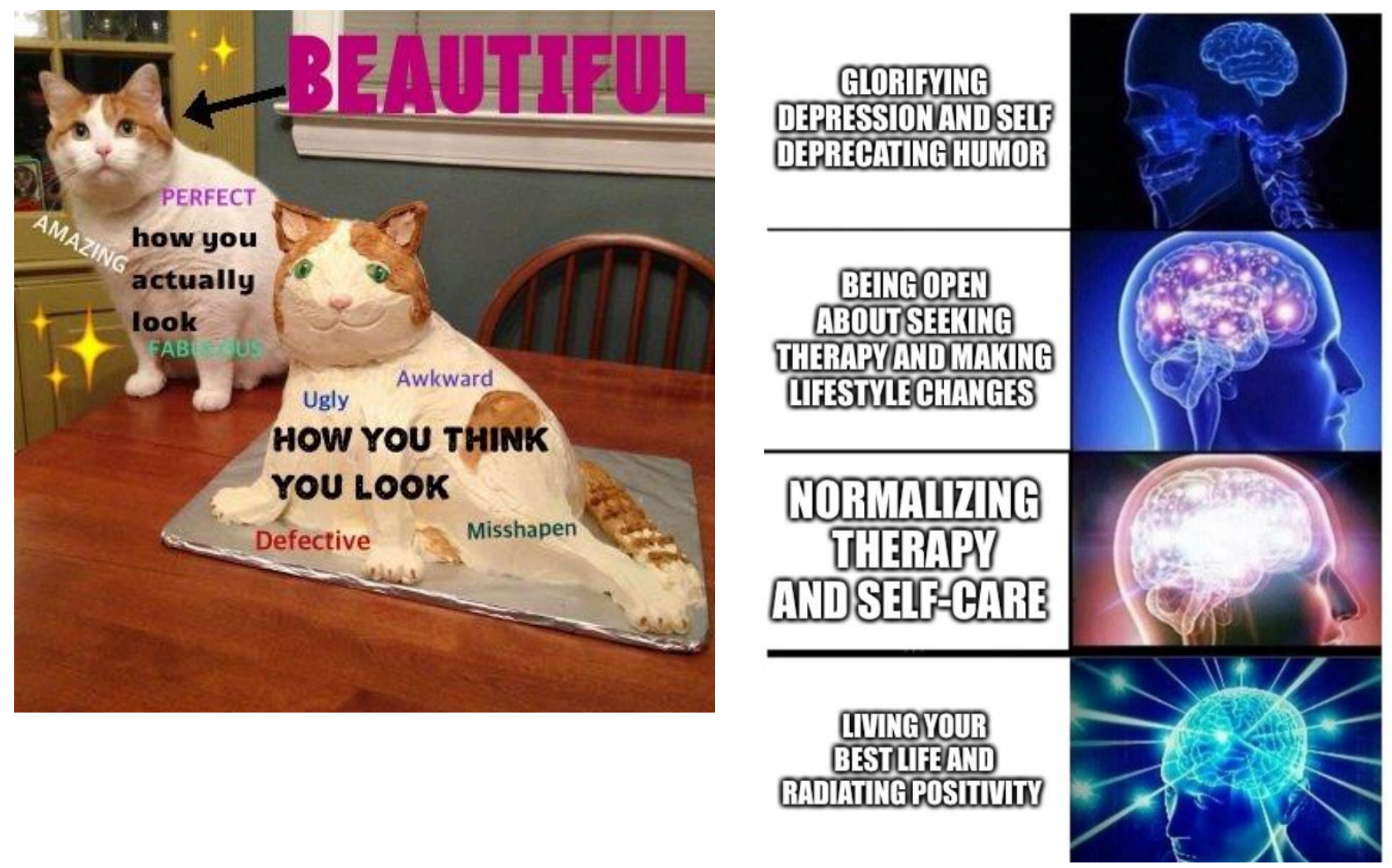

Figure 1: Examples of wholesome memes from Tumblr (L) and Reddit's r/wholesomememes $(R)$

Wholesome memes generally revolve around themes such as meaningful family relationships, friendships, or romantic partnerships. Animals or human-animal relationships are also common, with dogs and cats dominating the field. Visually, wholesome memes are frequently generated from screen captures of text from other social media platforms (e.g. Twitter, Tumblr, Facebook). These memes often feature feel-good stories or messages of thanksgiving and frequently include images of cute animals (Figure 2). 


\section{there's a lot of negativity on twitter rn, so \\ enjoy this wholesome meme. look at \\ that lil guy enjoyin his hamtaro}

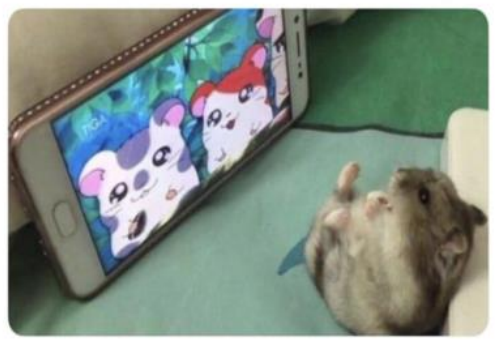

$8 / 4 / 18,10: 37$ PM

1,743 Retweets 3,858 Likes

Figure 2: A screen capture wholesome meme originally captured from Twitter

As the genre has progressed, wholesome memes have also adopted the memetic tactics of their non-wholesome cousins--deliberately subverting the tropes and templates of more traditional sarcastic or ironic memes to convey their wholesome message. Nagesh (2018) writes that "a lot of the posts take some of the internet's most disturbing memes and cover them with hearts and rainbows." These deliberately crude or sloppy modifications of the non-wholesome originals both acknowledge their bleak source material, while supplanting it with overwhelming positivity (Figure 3). There is a "grotesqueness" in these memes that helps to signal or amplify their subversive nature, as if to reclaim the meme format in the name of wholesomeness. "The creators of these memes are aware of the jokes that widespread image memes represent but use them to display warmth and empathy" (Feldman, 2016).

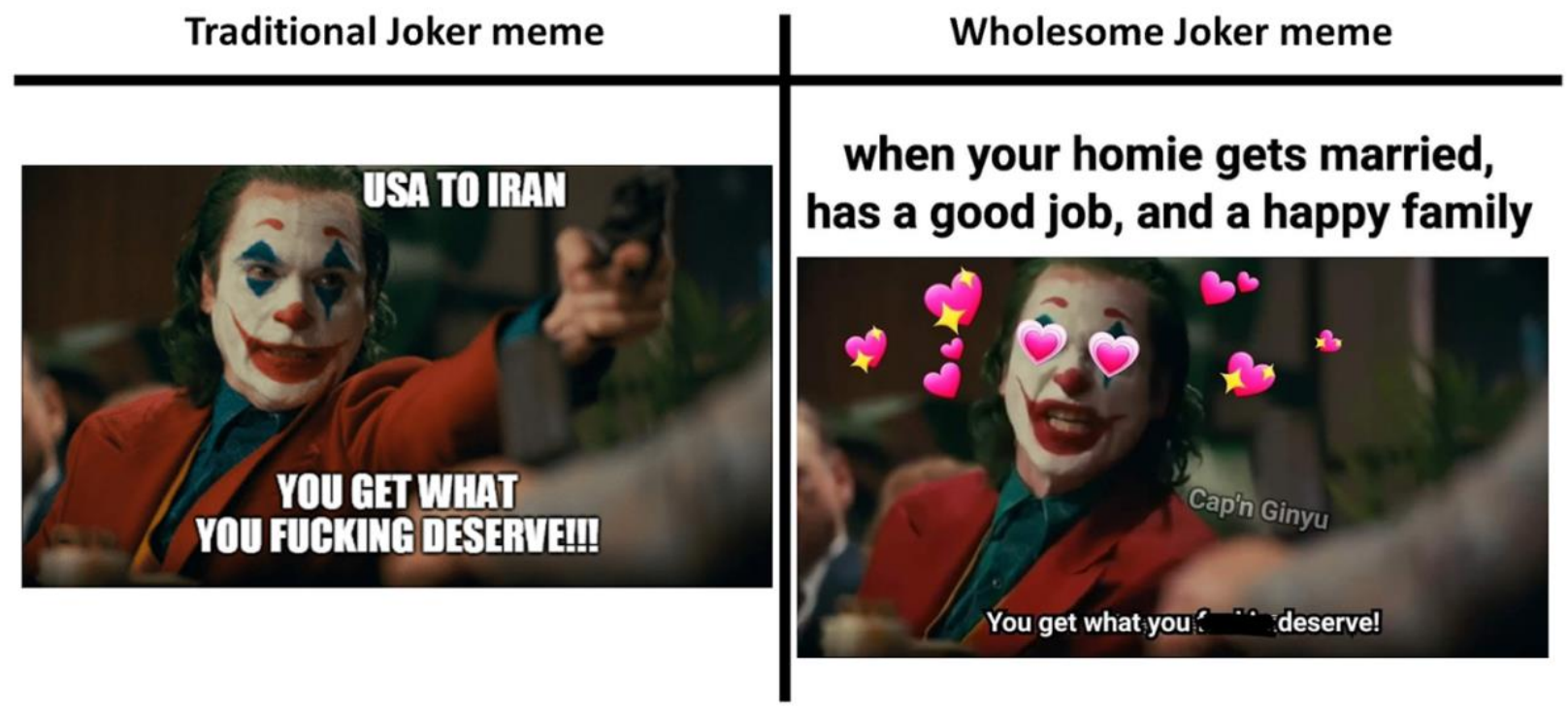

Figure 3: Parallel examples of non-wholesome and wholesome memes from Facebook 


\section{Wholesome memes as a reaction}

The encyclopedic website Know Your Meme documented the emergence of the wholesome meme in the early months of 2016 with the posting of early wholesome memes and the establishment of dedicated online spaces for them (Wholesome memes, 2018). This was also the period in history that saw Donald Trump win both the Republican nomination and then the United States presidency, based in no small part on the online support garnered through his provocative social media use.

While many online spaces have historically been "mischievous" at best (Kirman, et al., 2012) and "toxic" at worst (Massanari, 2017), the Trump campaign seemed especially adept at engaging the darkest of the "meme culture" communities (including 4chan and the r/the donald subreddit), inspiring a proliferation of alt-right activity (Onge, 2018). It was in this poisoned social media environment that wholesome memes began to flourish. Much of the popular writing about wholesome memes points to their emergence and ascendance as a reaction to the geopolitics of that time. Eadiccico (2017) posits that the wholesome meme is a "direct response to the negativity of the 2016 presidential election," while Romano (2018) points more broadly to a "geopolitical era that is unprecedented in recent memory for its turbulence and polarization." At a time when the entire world appeared to be in crisis, many memers seemed to have rejected ironic nihilism in favour of aggressive optimism.

Wholesome memes, then, can be viewed as a reaction to the political, social, and economic hopelessness of recent years which seeks to move away from these dominant negative cultural trends and towards something that is deliberately and emphatically the opposite. Romano (2018) describes wholesome memes as a type of remedy: "people appear to be using memes and cute pictures and videos to mitigate anxiety, as a form of wellness and self-care. For many, they offer a way to cope during times of tension and stress." Furthermore, "memes that center on compassion and self-preservation are, if in a small way, altering the way we speak to one another online" (Bryan, 2018). The creation and sharing of wholesome memes may point to a shift away from a hostile, polarized internet and towards a more nurturing one.

\section{Wholesome memes as The New Sincerity}

Building upon the above characterizations of wholesome memes as a response to traditional ironic meme culture becoming increasingly untenable, we argue that wholesome memes are post-ironic, in both a compositional sense (their image and text display multiple levels of meaning) as well in an absolute sense wherein these memes seek to move beyond or supplant the dominant ironic themes of non-wholesome memes. We situate these memes as part of a wider response (in literature and culture) to postmodernism, specifically, within the post-postmodernist literary movement called The New Sincerity. The New Sincerity is "conceived of as either a reactionary turn to or nostalgia for a 'preironic' sincerity, or a 'post-postmodern' hybrid or synthesis of irony and sincerity (or, indeed, an amalgamation of these two positions)" (Williams, 2015 , p. 301). It is a reaction to the "exclusively negative function" of irony, "critical and destructive" (Wallace, 1993, p. 183). Wholesome memes, with their heartfelt messages and rainbows crudely plastered over sarcastic meme templates, bring this synthesis of irony and sincerity into the medium of memes. 
Balliro (2018) further defines The New Sincerity as "a mode of interpretation defined by an intense focus on identifying and fostering coherent connections between readers and literary texts" (p. 1). In the case of wholesome memes, this means that the primary positive message of the meme is not to be subjected to ironic interpretation by the reader (although other elements of the meme may be, given its post-ironic and subversive qualities as well). The connection between wholesome meme creator and wholesome meme reader is meant to be untarnished and genuine; the sincerity of the author is intended to be maintained. The reader however must engage in this act of interpretation, of maintaining this relationship with the author. The New Sincerity is also concerned about power, writ large, and a seemingly existential struggle for independence and freedom. Suffering from the fragmentation of deconstructionist movements typical of the postmodern, Balliro (2018) suggests that "The New Sincerity are constantly on the lookout for connections that can be made in spite of these theories [e.g. Foucault's biopolitics, Derrida's deconstruction] — fragments that can be rearranged into a discernible whole, messages and theories of thought that can be pieced together to suggest opportunities for autonomy" (p. 9). Autonomy here speaks to one's ability to construct one's self in the face of the structural power that otherwise shapes self and society. The term autonomy here is connected with a sense of authenticity, in the Heideggerian sense (Eigentlichkeit). If one is not genuinely being one's own, or living for one's self, as Heidegger would describe the opposite of authenticity, then one is living life uncritically, befallen to culture and society. Wholesome memes, as part of The New Sincerity, provide the opportunities for connection that Barillo mentions. The creation and consumption of wholesome memes acts as a tool to restore and invigorate one's self with the sense of power that was lost to those theories that would cast power outside the self.

\section{Conclusion}

What might be the utility of understanding wholesome memes as a manifestation of the New Sincerity? There is growing recognition of the influence and impact of internet memes, in general. From commercial advertising (Pierno, 2018), to political participation (Ross \& Rivers, 2017), to charitable initiatives (Yang, Park, \& Lee, 2016), memes have proven to be powerfully effective tools for spreading messages to vast numbers of people. Could wholesome memes not also be harnessed in similar fashion to spread happy and healthy messages across an ambivalent internet? Framed within the context of LIS, can these happy and healthy documents and the information they contain contribute to a meaningful life? While wholesome memes are relative newcomers to internet culture and have not yet been fully investigated nor widely taken up by internet scholars, we argue here that they may be indicative of a turning point in the character and attitude of internet culture from anti- to pro-social. "Memes help create a shared set of attitudes... and provide members of a community ways to act on those attitudes" (Onge, 2018, p. 188). This pro-social attitude often aligns with the pro-social missions of libraries. While meme usage in official communications by libraries remains infrequent, perhaps wholesome memes can become part of the set of communicative tools used by libraries to target their Millennial and Gen Z users. 


\section{References}

Balliro, M. (2018). The New Sincerity in American literature (Doctoral dissertation). University of Rhode Island, South Kingstown, RI.

Bryan, C. (2018, Mar 7). Wholesome memes aren't just cute, they're subversive as $\mathrm{h}$ *ck. Mashable. Retrieved from https://mashable.com/2018/03/07/wholesome-memes/

Di Martino, L. (2014). Postmodern irony. In S. Attardo (Ed.), Encyclopedia of humor studies (pp. 589-592). Thousand Oaks, CA: Sage.

Eadicicco, L. (2017). How the internet is getting a little nicer, one meme at a time. Time, 189(23), 19-20.

Feldman, B. (2016). The next frontier in Internet culture is wholesome memes about loving your friends. New York Magazine. Retrieved from http://nymag.com/intelligencer/2016/08/the-nextfrontier-in-internet-culture-is-wholesome-memes.html

Frey, L., Botan, C., \& Kreps, G. (1999). Investigating communication: An introduction to research methods (2nd ed.). Boston, MA: Allyn \& Bacon.

Heylighen, F., \& Chielens, K. (2009). Cultural evolution and memetics. In B. Meyers (Ed.), Encyclopedia of complexity and system science. Retrieved from http://pespmc1.vub.ac.be/Papers/Memetics-Springer.pdf

Hunt, E. (2016, Aug 12). 'Wholesome memes': Could they mean more good times, online? The Guardian. Retrieved from https://www.theguardian.com/technology/2016/aug/13/wholesomememes-could-they-mean-more-good-times-online

Jang, S. M., Park, Y. J., \& Lee, H. (2017). Round-trip agenda setting: Tracking the intermedia process over time in the ice bucket challenge. Journalism, 18(10), 1292-1308.

Kari, J., \& Hartel, J. (2007). Information and higher things in life: Addressing the pleasurable and the profound in information science. Journal of the American Society of Information Science and Technology, 58(8), 1131-1147.

Kirman, B., Lineham, C., \& Lawson, S. (2012). Exploring mischief and mayhem in social computing or: how we learned to stop worrying and love the trolls. In CHI'12 Extended Abstracts on Human Factors in Computing Systems (pp. 121-130).

Massanari, A. L. (2017). \#Gamergate and The Fappening: How Reddit's algorithm, governance, and culture support toxic technocultures. New Media \& Society, 19, 329-346.

Nagesh, A. (2018. Apr 9). People are sharing \#wholesomememes to make the internet a bit less grim. BBC Three. Retrieved from https://www.bbc.co.uk/bbcthree/article/0ea8d63e-7b62-4e98968d-4bale975d8ed 
Onge, J. S. (2018). The circulation of rage: Memes and Donald Trump's presidential campaign. In Affect, Emotion, and Rhetorical Persuasion in Mass Communication (pp. 183-194).

Abingdon, United Kingdom: Routledge.

Pierno, A. (2018, Jul 16). How brands can use memes to connect with consumers in a new way. Adweek. Retrieved from https://www.adweek.com/creativity/how-brands-can-use-memes-toconnect-with-consumers-in-a-new-way

R/Wholesomememes. (n.d.) Reddit. Retrieved from https://www.reddit.com/r/wholesomememes/

Romano, A. (2018). The rise of the wholesome internet meme. Vox. Retrieved from https://www.vox.com/2018/10/3/17923096/wholesome-memes-trend-explained

Ross, A. S., \& Rivers, D. J. (2017). Digital cultures of political participation: Internet memes and the discursive delegitimization of the 2016 US Presidential candidates. Discourse, Context \& Media, 16, 1-11.

Wallace, D. F. (1993). E unibus pluram. Review of Contemporary Fiction, 13(2), 151-194.

Williams, I. (2015). (New) Sincerity in David Foster Wallace's “Octet". Critique: Studies in Contemporary Fiction, 56(3), 299-314.

Wholesome memes. (2018). Know your meme. Retrieved from https://knowyourmeme.com/memes/wholesome-memes 